\title{
Power Quality in Grid-Connected Wind Turbines
}

\author{
J.J. Gutierrez, J. Ruiz, P. Saiz, I. Azcarate, L.A. Leturiondo and A. Lazkano \\ University of the Basque Country \\ Spain
}

\section{Introduction}

Electric power is a very unusual product. It must be constantly available for the customers but its massive storage is not possible. Therefore, electric power needs to be generated as it is used. Furthermore, it is usually generated far from the customers. All these factors make it difficult to control and assure the quality of electric power. There is no procedure that allows the removal of the poor electric power. Consequently, it is necessary to define preventive and monitoring procedures that guarantee a minimum level of power quality and hence the correct behavior of the equipment connected to the power distribution system. Perfect power quality means that the voltage is continuous and sinusoidal with a constant amplitude and frequency. Low-frequency conducted disturbances are the main defects that could compromise power quality. These are classified in the following groups: harmonics and interharmonics, voltage dips and short supply interruptions, voltage unbalance, power frequency variations and voltage fluctuations or flicker.

In the last years the use of wind farms and other distributed power generation systems has drastically increased. The question that needs to be raised is how those new generation systems will affect to the whole grid. A portion of the answer must be obtained from the impact that they have on the power quality. In principle, wind energy can be considered a risky source in terms of power quality. Moreover, when wind turbines are part of the grid the power, quality seems to be a complex issue which highly depends on the interaction between the grid and the wind turbines. The main impact on the grid by the wind turbines, concerning power quality, is related to voltage changes and fluctuations, harmonic content, power peaks and flicker. The presence of these disturbances is determined by meteorological conditions and by the technical features of the wind turbine: continuously variable output power due to wind shear, tower shadow or turbulences; performance of electrical components such as generators and transformers; aerodynamic and mechanical behavior of the rotor...

The power quality of the wind turbines must be certified on the basis of measurements performed according to international standards and guidelines. On one hand, the IEC 61400-21 standard is the reference normative for the certification of the power quality of wind turbines (IEC-61400-21 Ed. 2.0, 2008). The first edition was published in 2001 and it specifies the main relevant features of power quality that should be measured in a wind turbine. This standard establishes the procedures for the measurement and assessment of power quality characteristics of grid-connected wind turbines. According to it, measurements should be performed for harmonic content, flicker, voltage drops as well as active and reactive power, during normal and switching operations. To obtain those characteristics, the measurements should be made on the basis of long time-series of current and voltage, always depending on 
wind conditions. On the other hand, the international Measuring Network of Wind Energy Institute (MEASNET) has defined some guidelines based on the above-mentioned standard with the aim to adapt the procedures and hence the measurement results obtained by its members.

This chapter is organized in two main related sections. The first section provides a descriptive approach to the main factors that have an influence on the power quality of the grid-connected wind turbines. First we summarize the main rationale and objectives of the IEC 61400-21 standard. Then we detail the procedures specified by the standard for the measurement of the main parameters of the wind turbine power quality characteristics: harmonic content, flicker, voltage drops and power parameters. We also focus on the most relevant features that must be considered by a measurement system when trying to assess one of the most complex power quality parameters: flicker. In the second section we describe our own measurement system, a useful tool specifically developed for the assessment of the power quality of a grid-connected wind turbine, according to the IEC 61400-21 standard. To conclude the chapter, we provide some illustrative examples of power quality parameters measured on different wind turbines installed in a wind farm of Northern Spain.

\section{Power quality characteristics of wind turbines}

Power injection from grid-connected wind turbines affects substantially the power quality. The procedures for the measurement and assessment of the main parameters involved in the power quality characteristics of a wind turbine are described in the IEC 61400-21 standard. The tests are designed to be as non-site-specific as possible, so that power quality characteristics measured with the wind turbine connected at a test site can also be considered valid at other sites.

The validity of the measurement procedure is dependent upon the proper establishment of the test conditions. The wind turbine has to be directly connected to the MV-network and the measurements of the electrical characteristics have to be made at the wind turbine terminals. It is necessary to specify the rated data of the wind turbine including rated active power of wind turbine $P_{n}$, rated apparent power $S_{n}$, nominal phase-to-phase voltage $U_{n}$ and the rated current $I_{n}$. Moreover, the location of the wind turbine terminals and the specific configuration of the assessed wind turbine including the relevant control parameter settings have to be clearly stated in the test report.

According to the standard there are seven parameters compromising the required power quality characteristics of a wind turbine: voltage fluctuations or flicker; harmonics and interharmonics; voltage drops; active power; reactive power; grid protection and reconnection time. In the following sections we will describe those parameters and the procedures specified for their measurement, stressing the most relevant issues affecting the assessment of harmonic and interharmonic content and flicker.

\subsection{Current harmonics, interharmonics and higher frequency components}

Voltage and current harmonics are usually present on the utility network. Non-linear and electronic loads, rectifiers and inverters, are some sources which produce harmonic content. The effects of the harmonics include overheating, faulty operation of protections, equipment failures or interferences with communication systems.

The standard specifically defines different procedures to assess the harmonics, interharmonics and higher frequency components for a wind turbine working under continuous conditions and operating with reactive power as close as possible to zero. This means that, if applicable, 
the reactive set-point control shall be set to zero. These parameters will not be considered under switching operations since the harmonic content is not harmful enough when the duration of the perturbation is limited to a short period of time.

The values of the individual current harmonics, interharmonics and higher frequency components and the Total Harmonic Current distortion (THC) must be provided in percentage of $I_{n}$ and with the wind turbine operating within the active power bins $0,10,20, \ldots$, $100 \%$ of $P_{n}$, where $0,10,20, \ldots, 100 \%$ are the bin midpoints. The harmonic current components must be specified as subgrouped RMS values for frequencies up to 50 times the fundamental grid frequency. The THC coefficient must be calculated from those values according to:

$$
T H C=\sqrt{\sum_{h=2}^{50} i_{s g, h}^{2}} \cdot 100
$$

where $i_{s g, h}=\frac{I_{s g, h}}{I_{n}}$ and $I_{s g, h}$ is the subgrouped RMS current harmonic of harmonic order $\mathrm{h}$. The interharmonic current components must be specified as subgrouped RMS values $I_{i s g, h}$ for frequencies up to $2 \mathrm{kHz}$ in accordance to Annex A of the IEC 61000-4-7 standard (IEC-61000-4-7, 2002). The higher frequency current components must be specified as subgrouped values for frequencies between $2 \mathrm{kHz}$ and $9 \mathrm{kHz}$ in accordance to Annex $\mathrm{B}$ of the IEC 61000-4-7 standard.

At least nine 10 min time-series of instantaneous current measurements (three tests and three phases) must be collected for each $10 \%$ power bin. The 10 min averages of each frequency band must be calculated for each 10 min time-series, and subsequently the maximum $10 \mathrm{~min}$ averages of each frequency band in each $10 \%$ power bin must be reported.

\subsubsection{Measurement of the subgrouped harmonic, interharmonic and higher frequency current components according to IEC 61000-4-7}

The measurement of the harmonic current content is specified for a discrete signal obtained at a sampling rate of $f_{s}$. The basic tool for the measurement is the Discrete Fourier Transform (DFT) applied over a signal window of $T_{w}$ seconds $\left(T_{w} \cdot f_{s}\right.$ samples). This transformation provides the spectral components for the analyzed window with a spectral resolution of $f_{w}=$ $\frac{1}{T_{w}} \mathrm{~Hz}$.

The standard suggests the use of a rectangular window whose duration is 10 cycles of the fundamental frequency in $50 \mathrm{~Hz}$ systems and 12 cycles in $60 \mathrm{~Hz}$ systems (i.e. approximately $0.2 \mathrm{~s}$ ). With these exact window lengths the spectral leakage has no influence on those spectral components that are a multiple number of the spectral resolution $f_{w}=5 \mathrm{~Hz}$. To achieve this goal it is necessary to use a sampling rate locked to the fundamental frequency by means of a Phase Locked Loop system (PLL).

Finally, to measure the spectral components up to $9 \mathrm{kHz}$ it is needed the use of a sampling rate over $18 \mathrm{kHz}$.

2.1.1.1 Calculation of the subgrouped harmonic, interharmonic and higher frequency current components.

The DFT applied to each window provides the spectral components, $c_{k}$, with a resolution of $5 \mathrm{~Hz}$ from the DC component up to $\frac{f_{s}}{2}$. Fig. 1 shows how the subgrouped harmonic and interharmonic components are grouped. The values of the components can be obtained by 
grouping the different spectral components from the DFT, according to the next equations:

$$
\begin{aligned}
& I_{s g, h}^{2}=\sum_{i=-1}^{1} c_{k+i}^{2} \\
& I_{i s g, h}^{2}=\sum_{i=2}^{p} c_{k+i}^{2}
\end{aligned}
$$

where the $k$ index refers to the spectral line order provided by the DFT, corresponding to the $h$-th harmonic component ( $k=10 \cdot h$ for $50 \mathrm{~Hz}$ systems and $k=12 \cdot h$ for $60 \mathrm{~Hz}$ systems). The value of $p$ must be 8 for $50 \mathrm{~Hz}$ systems and 10 for $60 \mathrm{~Hz}$ systems.

The values of the higher frequency components are obtained by grouping the spectral lines from the DFT in $200 \mathrm{~Hz}$ bands from 2 to $9 \mathrm{kHz}$. By using $k$ index for the spectral line corresponding to the band $\mathrm{b}=2100,2300, \ldots, 8900 \mathrm{~Hz}\left(k=\frac{b}{5}\right)$, the higher frequency component $I_{b}$ can be obtained as follows:

$$
I_{b}^{2}=\sum_{i=1-p}^{p} c_{k+i}^{2}
$$

The value of $p$ must be 20 for $50 \mathrm{~Hz}$ systems and 25 for $60 \mathrm{~Hz}$ systems.

\subsubsection{Smoothing process.}

For each $0.2 \mathrm{~s}$ window the equations (2) and (3) provide $I_{s g, h}, I_{i s g, h}$ and $I_{b}$ (this makes a total of 3000 values of each for every single value of $h$ or $b$, in case of $10 \mathrm{~min}$ time-series). To avoid abrupt transitions between different windows, the subgrouped current components obtained for each value of $h$ and $b$ are smoothed by processing those 3000 values through a $1^{\text {st }}$ low-pass filter with a time constant of $1.5 \mathrm{~s}$. This filter must be designed for a sampling frequency of $5 \frac{S}{s}$ because the $I_{s g, h}, I_{i s g, h}$ and $I_{b}$ values are available every $0.2 \mathrm{~s}$. Moreover, it is necessary to eliminate the first 50 values corresponding to the filter transient in order to obtain an accurate average of the 3000 values at the filter output.

\subsection{Response to voltage drops}

One of the main objectives of the IEC 61400-21 standard is to provide a methodology to be used in wind energy generation systems so that they contribute to control and assess the quality of service of the electric power system, as conventional plants do. Moreover, one of the main concerns related to the massive insertion of renewable energy generation systems, such as wind turbines, is to maintain the reliability of the system despite the contingencies that may happen in the network.

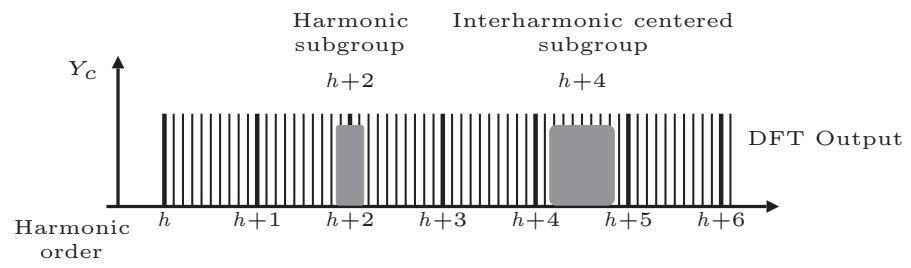

Fig. 1. Illustration of the harmonic subgroup and interharmonic centered subgroup. 
A specific problem is related to the behavior of the wind farms in the presence of voltage drops in the electrical network. Voltage drops are sudden voltage dips mainly caused by faults in the network. These events are random in nature and can be characterized by their amplitudes and duration. Previous experiences generate doubts about the capacity wind power generation to remain connected, both during the fault and during the subsequent recovery. The standard tries to check that wind farms are able to actively contribute to grid stability in case of voltage drops, and to that end a specific test is included in the standard.

This test is defined for off-line conditions, i.e. when the turbine under test is disconnected from the grid and therefore does not contribute to modify the voltage shape. The test verifies the response of a wind turbine to voltage drops, with the wind turbine operating at two different situations concerning the rated active power $P_{n}$ : between $10 \%$ and $30 \%$ of $P_{n}$ and above $90 \%$. A number of six voltage drops are defined, specifying the magnitude and duration of the rectangular voltage drop (see Table 1).

\begin{tabular}{lccc}
\hline Case & $\begin{array}{c}\text { Magnitude of voltage } \\
\text { phase to phase }\end{array}$ & $\begin{array}{c}\text { Magnitude of positive } \\
\text { sequence voltage }\end{array}$ & Duration(s) \\
\hline VD1 & $0.90 \pm 0.05$ & $0.90 \pm 0.05$ & $0.5 \pm 0.02$ \\
VD2 $^{1}$ & $0.50 \pm 0.05$ & $0.50 \pm 0.05$ & $0.5 \pm 0.02$ \\
VD3 $^{1}$ & $0.20 \pm 0.05$ & $0.20 \pm 0.05$ & $0.2 \pm 0.02$ \\
VD4 $^{2}$ & $0.90 \pm 0.05$ & $0.95 \pm 0.05$ & $0.5 \pm 0.02$ \\
VD5 $^{2}$ & $0.50 \pm 0.05$ & $0.75 \pm 0.05$ & $0.5 \pm 0.02$ \\
VD6 $^{2}$ & $0.20 \pm 0.05$ & $0.60 \pm 0.05$ & $0.2 \pm 0.02$ \\
\hline
\end{tabular}

${ }^{1}$ Symmetrical three-phase voltage drop

2 Two-phase voltage drop

Table 1. Specification of the test of voltage drops.

These test signals are used in the measurement procedure to obtain time-series of active power, reactive power, current and voltage at the wind turbine terminals for the time shortly prior to the voltage drop and until the effect of the voltage drop has extinguished. The test can be carried out using a set-up, such as in Fig. 2, in which the voltage drops are created by a short-circuit emulator that connects the three phases or two phases to ground via an impedance, or connecting the three or two phases together through an impedance.

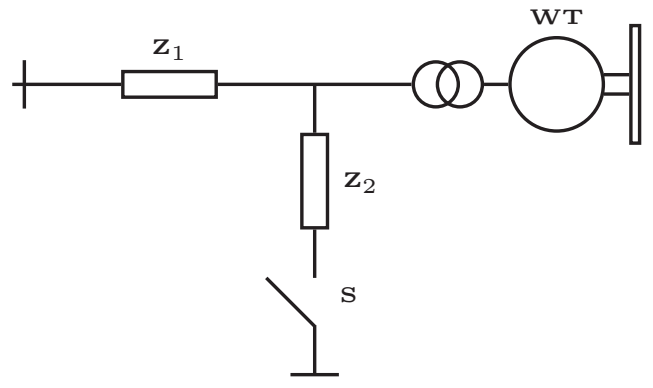

Fig. 2. System with short circuit emulator for testing wind turbine response to temporary voltage drops.

The voltage drop is created by connecting the impedance $Z_{2}$ by the switch $S$, which shall be able to accurately control the time between connection and disconnection of $Z_{2}$. The 
impedance value of $Z_{2}$ must be set to obtain the voltage magnitudes specified in the standard when the wind turbine is not connected. The function of impedance $Z_{1}$ is to limit the effect of the short-circuit on the up-stream grid. The magnitude of this impedance should be selected so that the voltage drop tests do not cause an unacceptable situation at the upstream grid, and at the same the impedance does not affect the transient response of the wind turbine in a significant manner.

\subsection{Active and reactive power}

The standard tries to assess the capability of the wind turbine concerning the active and reactive powers. The assessment must be done by means of different types of tests, some of them based on the wind speed and others considering both the wind speed and the wind turbine regulation system.

\subsubsection{Active power}

For the assessment of the active power three different tests are considered. First, the maximum power must be measured from at least 5 time-series of $10 \mathrm{~min}$, collected for each $1 \frac{\mathrm{m}}{\mathrm{s}}$ wind speed bin between the cut-in wind speed and $15 \frac{\mathrm{m}}{\mathrm{s}}$. The measured power must be transferred to $0.2 \mathrm{~s}$ average data and $60 \mathrm{~s}$ average data by a block averaging:

- $P_{0.2}$ will be determined as the highest value obtained from $0.2 \mathrm{~s}$ windows, recorded during the 10 min period.

- $P_{60}$ will be determined as the highest valid $60 \mathrm{~s}$ value calculated by averaging the $0.2 \mathrm{~s}$ values, recorded during the $10 \mathrm{~min}$ period.

- $P_{600}$ will be determined as the highest $600 \mathrm{~s}$ value calculated by averaging the $0.2 \mathrm{~s}$ values, recorded during the $10 \mathrm{~min}$ period.

On the other hand, the ability of the wind turbine to operate in active power set-point control mode and to operate in ramp rate limitation control mode must be tested. For both tests, the results will be the active power calculated from $0.2 \mathrm{~s}$ average data, the wind speed and the available active power. The available active power must be obtained from the control system of the wind turbine. If the wind turbine control system does not provide it, an approximate value can be used based on measured wind speed combined with the power curve of the wind turbine.

In the case of ramp rate limitation, the wind turbine must be started from stand still and the ramp rate must be set to $10 \%$ of rated power per minute. Moreover, the available active power output must be at least $50 \%$ of rated power. In the case of set-point control, the test must be carried out during a test period of $10 \mathrm{~min}$. The ramp rate limitation must be deactivated during this test and the set-point signal must be reduced from $100 \%$ to $20 \%$ in steps of $20 \%$ during 2 min at each set-point value. Moreover, the available active power output must be at least $90 \%$ of rated power.

\subsubsection{Reactive power}

For the assessment of the reactive power two different tests are considered. Both tests must be done considering the regulation system of the wind turbine.

The first test tries to assess the capability of the wind turbine concerning the maximum inductive reactive power and the maximum capacitive reactive power. For each of the two settings, the measurements must be taken so that at least 30 time-series of $1 \mathrm{~min}$ of active and 
reactive power are collected at each $10 \%$ power bin from $0 \%$ to $100 \%$. The sampled data will be calculated as $1 \mathrm{~min}$ average data by applying $0.2 \mathrm{~s}$ block averaging for each $1 \mathrm{~min}$ period. On the other hand, the reactive power control by set-point value must also be measured, considering two cases: the measurement at a set-point of reactive power at zero and the measurement during the step change of reactive power. For the first case, the procedure is the same as that one used to assess the capability of the wind turbine concerning the maximum reactive power. For the second case, the test must be of $6 \mathrm{~min}$ period and the set-point of reactive power must be regulated for $2 \mathrm{~min}$ intervals corresponding to reactive power of zero, maximum capacitive reactive power and maximum inductive reactive power. The active power output, measured as $1 \mathrm{~min}$ average values, must be approximately $50 \%$ of rated power. The reactive power must be $0.2 \mathrm{~s}$ average data.

The results of the test must be the reactive power from $0.2 \mathrm{~s}$ windows, together with the set-point value of reactive power.

\subsection{Voltage fluctuations (Flicker)}

The impression of unsteadiness of visual sensation induced by variation in the intensity of a light source due to fluctuations of the supply voltage is known as flicker.

As a result of the subjective nature of the perception of annoyance related to the sensitivity of each person to light fluctuations, the precise measurement of flicker is not an easy task. IEC 61000-4-15 provides a detailed description of the structure and functional specifications of flicker measuring device called flickermeter. This measurement tool represents the relationship between voltage fluctuations and the human discomfort providing a short-term, $P_{s t}$, and a long-term, $P_{l t}$, indicator. The $P_{s t}$ is the flicker severity evaluated over a short period (10 minutes is used in practice) and the conventional threshold of irritability is set in $P_{s t}=1$. The $P_{l t}$ term is the flicker severity evaluated over a long period of two hours and it is obtained by using successive $P_{s t}$ values.

Fluctuating loads in the electrical power system, e.g. welding machines, arc furnaces or electric boilers, are the main sources of these perturbations in the electrical power system. Moreover, from the point of view of power generation, the connection of wind turbines to the grid can affect the ideal form of the voltage signal. Among the perturbations generated by the wind turbines, the fluctuations in voltage are the most notable (Ackerman, 2005). Rapid variations in wind speed produce fluctuating power, which can lead to voltage fluctuations at the Point of Common Coupling (PCC), which in turn generate flicker. The standard specifies a test for the voltage fluctuations with the aim of obtaining the measurements independently of the characteristics and conditions of the network to which the wind turbine is connected. Furthermore, the standard requires the characterization of the voltage fluctuations for two situations, namely continuous operation and switching operations.

The following paragraphs will describe the test procedures for both types of functional conditions.

\subsubsection{Continuous operation}

It is described as the normal operation of the wind turbine excluding start-up and shut-down operations. The standard establishes a processing and statistical evaluation scheme to obtain the flicker coefficients (see Fig. 3). These coefficients must be estimated from the current and voltage time-series measured during the continuous operation.

The specification establishes a specific test procedure with the aim of obtaining a normalized measure of the flicker emission. The phase-to-neutral voltage and the line current, $u_{m}(t)$ and 


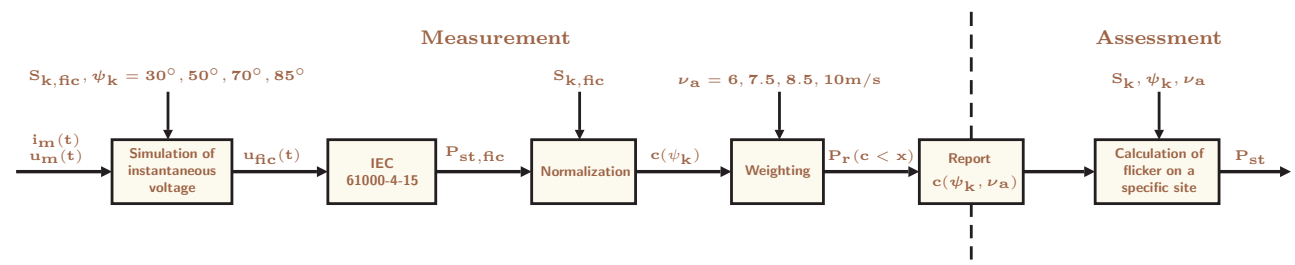

Fig. 3. Scheme of the measurement and assessment procedures for flicker during continuous operation of the wind turbines in accordance with IEC 61400-21.

$i_{m}(t)$, need to be processed for at least 15 registers of 10 min duration for each $1 \frac{\mathrm{m}}{\mathrm{s}}$ wind speed bin between the cut-in wind speed and $15 \frac{\mathrm{m}}{\mathrm{s}}$. For each time-series and for each network impedance, specified in the standard with the values of $30^{\circ}, 50^{\circ}, 70^{\circ}$ and $85^{\circ}$, the fictitious voltage $u_{f i c}(t)$ is calculated from the circuit of Fig. 4 . This model represents a fictitious grid that enables the assessment of flicker caused exclusively by the wind turbine. In compliance with IEC 61000-4-15 and using the fictitious voltage $u_{f i c}(t)$ as the input to the flickermeter, a flicker emission value, $P_{s t, f i c}$, can be obtained.

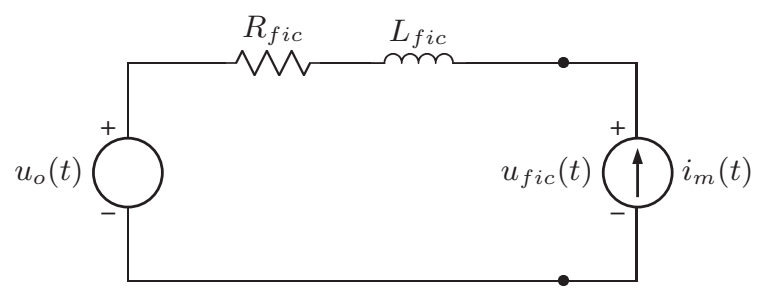

Fig. 4. Fictitious grid used for flicker assessment in wind turbines.

The flicker coefficient has to be determined for each of the calculated flicker emission values by applying the equation (4):

$$
c\left(\psi_{k}\right)=P_{s t, f i c} \cdot \frac{S_{k, f i c}}{S_{n}}
$$

where $S_{n}$ is the rated apparent power of the wind turbine and $S_{k, f i c}$ is the short-circuit apparent power of the fictitious grid.

For each network impedance phase angle $\psi_{k}$, a weighting procedure calculates the weighted accumulated distribution functions of the flicker coefficients, $P_{r}(c<x)$, assuming four different Rayleigh distributed wind speeds of mean $v_{a}=6,7.5,8.5$ and $10 \frac{\mathrm{m}}{\mathrm{s}}$. For each accumulated distribution, the $99 \%$ percentile, $c\left(\psi_{k}, v_{a}\right)$, of the flicker coefficient is then reported.

The assessment procedure specifies how the reported flicker coefficients can be used to estimate the flicker emission from a single wind turbine or a group of wind turbines. The short and long-term flicker emission from the wind turbine installation must be compared with the short and long-term flicker emission limits for the relevant PCC, and with that purpose, these flicker emission terms must be obtained as follows:

$$
P_{s t}=c\left(\psi_{k}, v_{a}\right) \cdot \frac{S_{n}}{S_{k}}
$$


where $c\left(\psi_{k}, v_{a}\right)$ is the flicker coefficient of the wind turbine, $S_{n}$ is the rated apparent power of the wind turbine and $S_{k}$ is the short-circuit apparent power at the PCC.

In case more wind turbines are connected to the PCC, the flicker emission due to the sum of them can be estimated as:

$$
P_{s t \Sigma}=\frac{1}{S_{k}} \cdot \sqrt{\sum_{i=1}^{N_{w t}}\left[c_{1}\left(\psi_{k}, v_{a}\right) \cdot S_{n, i}\right]^{2}}
$$

where $c_{i}\left(\psi_{k}, v_{a}\right)$ is the flicker coefficient of the individual wind turbine, $S_{n, i}$ is the rated apparent power of the individual wind turbine and $N_{w t}$ is the number of wind turbines connected to the PCC.

\subsubsection{Switching operations}

The standard establishes an alternative processing and statistical evaluation scheme during start-up or switching between generators (see Fig. 5). Four different parameters must be obtained to assess the consequences of the start-up and shut-down maneuvers of the wind turbine: the maximum number of switching operations within a $10 \mathrm{~min}$ and 2 hour period, $N_{10_{m}}$ and $N_{120_{m}}$ respectively, the flicker step factor $k_{f}\left(\psi_{k}\right)$ and the voltage change factor $k_{u}\left(\psi_{k}\right)$.

The specification establishes a procedure of measurements and subsequent calculations to determine $k_{u}\left(\psi_{k}\right)$ and $k_{f}\left(\psi_{k}\right)$ for each type of switching operation. The phase-to-neutral voltage and the line current, $u_{m}(t)$ and $i_{m}(t)$, need to be processed for at least 15 registers of a period $T_{p}$ long enough to pass the transient of the switching operation. As in the case of the continuous operation, the fictitious voltage, $u_{f i c}(t)$, and the flicker emission values, $P_{s t, f i c}$, are calculated. Flicker step factor and voltage change factor can be obtained by applying the expressions (7) and (8) respectively, and finally they are determined as the average result of the 15 calculated values.

$$
\begin{gathered}
k_{f}\left(\psi_{k}\right)=\frac{1}{130} \frac{S_{k, f i c}}{S_{n}} \cdot P_{s t, f i c} \cdot T_{p}^{0,31} \\
k_{u}\left(\psi_{k}\right)=\sqrt{3} \cdot \frac{U_{f i c, \text { máx }}-U_{f i c, \text { min }}}{U_{n}} \cdot \frac{S_{k, f i c}}{S_{n}}
\end{gathered}
$$

where $U_{f i c, m a x}$ and $U_{f i c, m i n}$ are the maximum and minimum one period root mean square (RMS) value of the voltage on the fictitious grid during the switching operation.

The assessment procedure for switching operations specifies how to estimate the flicker emission and voltage changes during switching operations on any specified site, using the reported flicker step factors and voltage change factors.

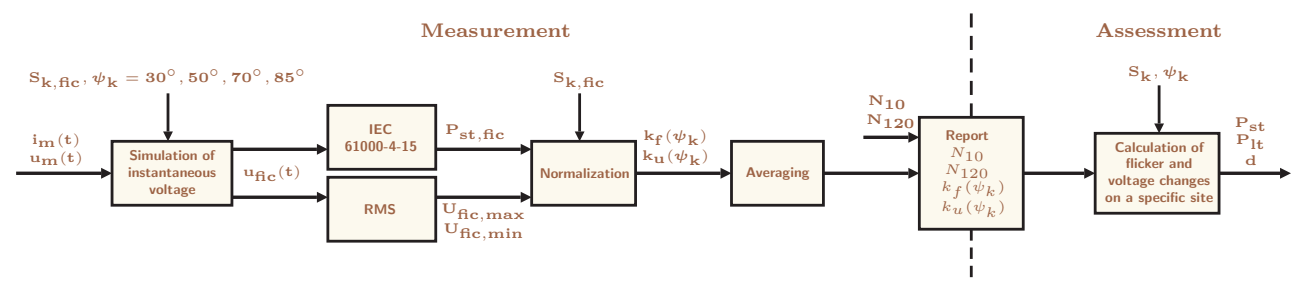

Fig. 5. Measurement and assessment procedures for flicker during switching operations of the wind turbines in accordance with IEC 61400-21. 
During the assessment procedure, the established flicker emission limits must be compared with the short and long-term flicker parameters that can be obtained from the next expressions:

$$
\begin{gathered}
P_{s t}=18 \cdot N_{10_{m}}^{0.31} \cdot K_{f}\left(\psi_{k}\right) \cdot \frac{S_{n}}{S_{k}} \\
P_{l t}=8 \cdot N_{120_{m}}^{0.31} \cdot K_{f}\left(\psi_{k}\right) \cdot \frac{S_{n}}{S_{k}}
\end{gathered}
$$

In the case that more wind turbines are connected to the PCC, the flicker emission from the sum of them can be estimated from equation (11) and equation (12):

$$
\begin{aligned}
& P_{s t \Sigma}=\frac{18}{S_{k}} \cdot\left(\sum_{i=1}^{N_{w t}} N_{10_{m, i}} \cdot\left[k_{f, i}\left(\psi_{k}\right) \cdot S_{n, i}\right]^{3.2}\right)^{0.31} \\
& P_{l t \Sigma}=\frac{18}{S_{k}} \cdot\left(\sum_{i=1}^{N_{w t}} N_{120_{m, i}} \cdot\left[k_{f, i}\left(\psi_{k}\right) \cdot S_{n, i}\right]^{3.2}\right)^{0.31}
\end{aligned}
$$

where $N_{10_{m, i}}$ and $N_{120_{m, i}}$ are the number of switching operations of the individual wind turbine within a $10 \mathrm{~min}$ and 2 hour period respectively, and $k_{f, i}(k)$ is the flicker step factor of the individual wind turbine.

\subsubsection{Relevant issues for the flicker test implementation}

There are two relevant aspects that should be considered when implementing the test procedure under both functional conditions, normal operation and switching operations. First, the estimation of the fictitious voltage obtained from the resolution of the fictitious grid specified by the IEC 61400-21 standard. Second, the implementation of the IEC flickermeter, according to the functional specifications defined by the IEC 61000-4-15 standard.

2.4.3.1 Estimation of the fictitious voltage.

IEC 61400-21 standard specifies a method that uses current and voltage time-series measured at the wind turbine terminals to simulate the voltage fluctuations on a fictitious grid with no source of voltage fluctuations other than the wind turbine. The fictitious grid is shown in Fig 4 . The turbine is represented by a current generator with a value of $i_{m}(t)$, and the network to which it is connected is represented by its Thevenin equivalent circuit and an ideal phase-to-neutral voltage source with the instantaneous value $u_{0}(t)$. The network impedance is composed of a resistance $R_{f i c}$ in series with an inductance $L_{f i c}$.

The ideal voltage source $u_{0}(t)$ models a network free of fluctuations and is defined as:

$$
u_{0}(t)=\sqrt{\frac{2}{3}} \cdot U_{n} \sin \alpha_{m}(t)
$$

The electrical angle $\alpha_{m}(t)$ of the fundamental can be described as:

$$
\alpha_{m}(t)=2 \pi \int_{0}^{t} f(t) d t+\alpha_{0}
$$

where $f(t)$ is the fundamental frequency, which may vary over time, and $\alpha_{0}$ is the electrical angle of the fundamental frequency at $t=0$. 
With this model a fictitious voltage, $u_{f i c}(t)$, at the wind turbine terminals can be obtained using the expression (15):

$$
u_{f i c}(t)=u_{0}(t)+R_{f i c} \cdot i_{m}(t)+L_{f i c} \cdot \frac{d i_{m}(t)}{d t}
$$

The main error source in the calculation of $u_{f i c}(t)$ appears from the estimation of $u_{0}(t)$, which must fulfill the following two conditions:

1. Flicker on the voltage $u_{0}(t)$ should be zero.

2. The ideal voltage source $u_{0}(t)$ should have the same electrical angle $\alpha_{m}(t)$ as the fundamental frequency of the measured voltage $u_{m}(t)$.

A small error in the estimation of the phase of the fundamental frequency of $u_{m}(t)$ can generate important changes in $u_{f i c}(t)$ that significantly affect the $P_{s t, f i c}$ value calculated (Gutierrez et al., 2008). To obtain an accurate estimation of $u_{0}(t)$ fulfilling the previous conditions, the selection of a proper signal processing technique turns out to be a key factor. First, it is important to understand that $u_{m}(t)$ is a band-limited signal and most of its power is concentrated around its fundamental frequency, which is equal or very close to $50 \mathrm{~Hz}$. As it has been demonstrated in previous works (Gutierrez et al., 2008), the obtention of a precise estimation of $u_{0}(t)$ entails necessarily the combination of two processes, applied to $u_{m}(t)$ :

- Filtering the fundamental frequency of $u_{m}(t)$. We propose the implementation of a narrow band adaptive filter, whose results can be improved by an anticausal zero-phase filter implementation.

- Calculation of the instantaneous phase of the fundamental frequency of $u_{m}(t)$ by implementing a classical zero-crossing method.

Next, we will describe the main technical considerations for a proper implementation of those processes.

1. Narrow band filter and anticausal zero-phase filter implementation.

The typical method of eliminating a narrow band interference consists of filtering the signal using a notch filter. Our case is the inverse, given that the objective is the fundamental component of the signal $u_{m}(t)$. Working in the discrete domain, a very narrow band-pass filter needs to be designed around the discrete pulsation corresponding to the fundamental frequency $\Omega_{0}=2 \pi \frac{f_{0}}{f_{s}}$ with $f_{0}=50 \mathrm{~Hz}$. A proper solution could be a narrow band-pass filter implemented through an adaptive scheme based on the Least Mean Square algorithm (LMS). This design makes it possible to obtain the fundamental component at $50 \mathrm{~Hz}$ without distortion and without any delay at the output with respect to the input (Widrow \& Stearns, 1985).

From the transfer function of the noise-canceller, the transfer function of the adaptive filter output can be calculated as:

$$
H(z)=1-H_{1}(z)=2 \mu C^{2} \cdot \frac{z \cos \left(\Omega_{0}\right)-1}{z^{2}-2\left(1-\mu C^{2}\right) z \cos \left(\Omega_{0}\right)+1-\mu C^{2}}
$$

corresponding to a $3 \mathrm{~dB}$ bandwidth $B W=2 \mu \mathrm{C}^{2} \mathrm{rad}=\frac{f_{s} \mu \mathrm{C}^{2}}{\pi} \mathrm{Hz}$.

The frequency response $H(\Omega)$ corresponds to a narrow band-pass filter that enables obtaining the fundamental component of $u_{m}[n]$. When working with $C=1, f_{s}=3200 \frac{S}{s}$ 


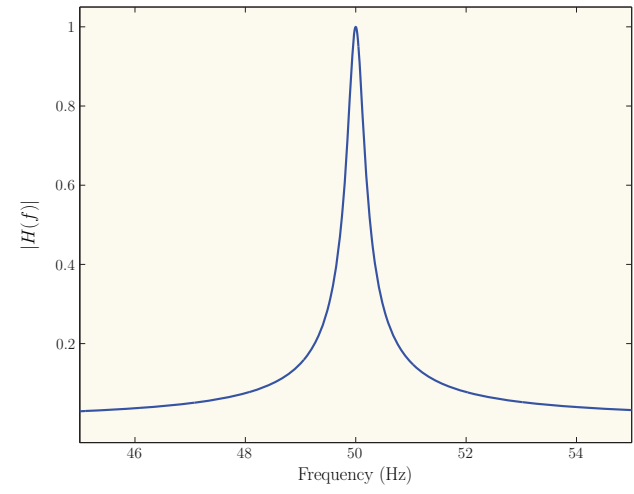

(a) Module of the band-pass filter frequency response.

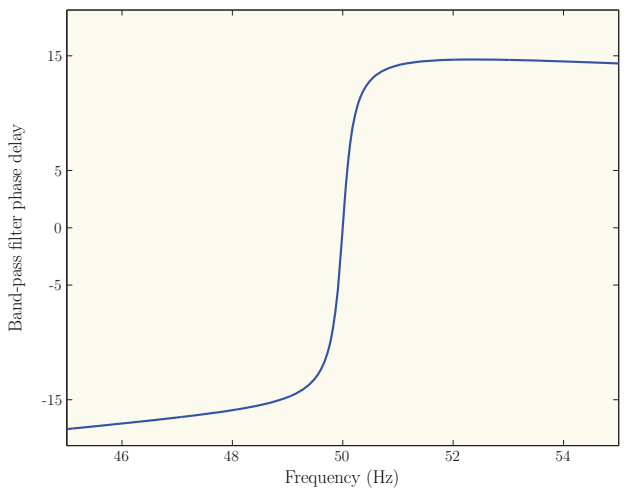

(b) Phase delay of the band-pass filter.

Fig. 6. Frequency responses of the band-pass filter.

and $\mu=0.0003$, a bandwidth of approximately $0.3 \mathrm{~Hz}$ is found around the $50 \mathrm{~Hz}$ component. Fig. 6 shows the module and the phase delay $\tau_{f}(\Omega)=\frac{-\phi(\Omega)}{\Omega}$ of $H(\Omega)$ scaling the axis of frequency in $\mathrm{Hz}$.

The main problem that $H(z)$ presents to obtain the fundamental component of $u_{m}[n]$ is the abrupt behavior of the phase delay around $50 \mathrm{~Hz}$, that produces displacements of several samples in the output due to eventual small variations of the fundamental frequency around $50 \mathrm{~Hz}$. This causes an appreciable error in the $P_{s t}$ of $u_{\text {fic }}(t)$. To solve this problem, the phase distortion can be eliminated using the Anticausal Zero-Phase Filter Implementation.

Considering the processing scheme in Fig. 7, after filtering in the forward direction, the filtered sequence is reversed and run back through the filter. The result has exactly zero-phase distortion. In fact, in the frequency domain $Y(\Omega)=U_{m}(\Omega) \cdot|H(\Omega)|^{2}$. The magnitude is the square of the filter's magnitude response, and the filter order is double the order of $H(z)$.

This implementation can only be used in cases in which $u_{m}[n]$ is a finite duration signal known before being filtered. From the signal obtained, $y[n]$, it is necessary to eliminate the transitory at both ends.

2. Zero-Crossing Method.

The estimation of the frequency of the power system using the zero-crossing technique has been well known for a long time (Lee \& Devaney, 1994). Constructing the instantaneous phase of the signal $u_{m}(t)$ from the frequency or period of each cycle of $u_{m}(t)$, is straightforward.

Working in the discrete domain, the algorithm searches for the positions of the contiguous samples of $u_{m}(t)$ that mark a transition of values from positive to negative. To achieve a

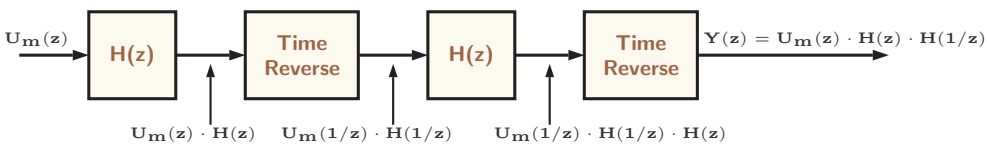

Fig. 7. The anticausal zero-phase filter scheme. 


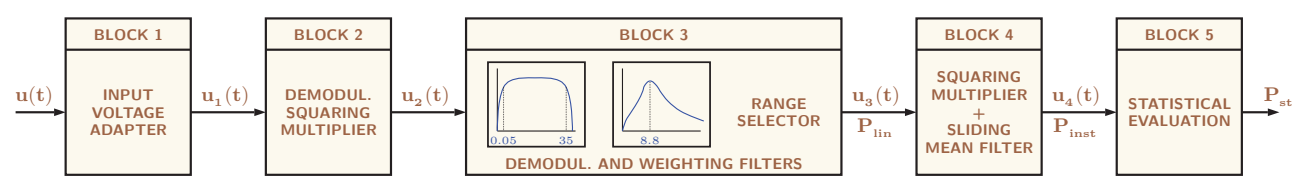

Fig. 8. Block diagram of the IEC flickermeter according to IEC 61000-4-15 (IEC-61000-4-15 Ed. 2.0, 2010).

more precise approximation to the zero-crossing point, a linear interpolation between the points of the transition can be used.

Knowing the number and the fraction of the samples that make up a period, reconstruction of the instantaneous phase of the fundamental component is done, sharing the $2 \pi$ radians uniformly for each sampling instant.

\subsubsection{Estimation of $\mathbf{P}_{\text {st,fic }}$}

Once the fictitious voltage $u_{f i c}(t)$ has been estimated, the standard specifies the calculation of the short-term flicker severity $P_{s t}$ produced by that voltage. The measurement of the flicker severity is a complex procedure whose functional specifications are detailed in the IEC 61000-4-15 standard, namely IEC flickermeter, and it is worth providing some details and relevant considerations about its implementation. Fig. 8 shows the block diagram of the IEC flickermeter.

Block 1 of the flickermeter scales the input voltage to an internal reference value. The objective of this block is to make flicker measurements independent of the input voltage level.

Block 2 recovers the voltage fluctuations by squaring the scaled input voltage, thereby simulating the behavior of an incandescent lamp.

Block 3 of the flickermeter consists of three cascaded filters, followed by a range selector that determines the sensitivity of the device. The first two filters are part of the demodulation process and consist of a first-order high-pass filter (cutoff frequency $=0.05 \mathrm{~Hz}$ ) and a sixth-order low-pass Butterworth filter (cutoff frequency $=35 \mathrm{~Hz}$ ). The third filter models the behavior of the lamp-eye system. The analogue response of this band-pass filter is defined in the standard for $230 \mathrm{~V}$ and $120 \mathrm{~V}$ reference lamps.

Block 4 implements an eye-brain model. It includes a squaring multiplier followed by a low-pass filter that is specified to be a sliding-mean filter, having the transfer function of a $1^{\text {st }}$-order low-pass resistance-capacitance filter with a time constant of $300 \mathrm{~ms}$. The output of Block 4 represents the instantaneous flicker sensation $P_{\text {inst }}$. A unit output from Block 4 corresponds to the reference human flicker perceptibility threshold. In Block 5, $P_{s t}$ is calculated by performing a statistical classification of $P_{\text {inst }}$ over a short period of time (usually $10 \mathrm{~min})$. The method for obtaining the $P_{s t}$ value is a multipoint algorithm that uses the percentiles obtained from the cumulative probability distribution of $P_{\text {inst }}$, namely

$$
P_{s t}=\sqrt{0.0314 \cdot P_{0.1}+0.0525 \cdot P_{1 s}+0.0657 \cdot P_{3 s}+0.28 \cdot P_{10 s}+0.08 \cdot P_{50 s}}
$$

For the measurements performed in this work, we have implemented a highly accurate IEC flickermeter. This reference flickermeter is the complete digital MatLab implementation previously used in other studies (Ruiz et al., 2007; 2010). Its main features are:

1. The input can be either analytically generated signals, as rectangular voltage fluctuations, or actual registered signals that have been digitally formatted. 
2. It uses any input sampling selected from these two sets: $f_{s}=1600,3200,6400,12800$ and $25600 \frac{S}{S}$ and $f_{S}=1280,2560,5120,10240$ and $20480 \frac{S}{S}$.

3. It performs a decimation process at the output of the sixth-order low-pass Butterworth filter to allow a constant sampling rate of $1600 \frac{S}{S}$ for the first set of sampling frequencies and $1280 \frac{S}{S}$ for the second, in the following blocks, independently of the input sampling rate.

4. To avoid errors coming from the classification process in terms of number of classes, type of classification or type of interpolation between the classes, our reference flickermeter does not classify the $P_{\text {inst }}$ signal. It stores all the samples of $P_{\text {inst }}$ during the short-term period of $10 \mathrm{~min}$ and calculates the percentiles of (17) in an absolutely accurate way.

5. Finally, it is important to remark that the complete precision of the reference flickermeter has been contrasted with other well-known implementations (Key et al., 1999; Mombauer, 1998), also used in previous works (Gallo et al., 2006; WG2CIGRÉ, 2004).

\section{A system for the measurement of the power quality characteristics of grid-connected wind turbines}

The assessment of the power quality characteristics of a wind turbine requires the obtention of several voltage and current time-series for different wind speeds. These time-series must be obtained for two types of functional status of the wind turbine: continuous and switching operations.

Moreover, all that information must be processed to measure several parameters, which requires, in principle, the connection of different power quality analyzers. There are not so many commercial analyzers particularly designed to fulfill the requirements of the IEC 61400-21 standard. Furthermore, there are very few research works about integrated systems to assess the power quality of grid-connected wind turbines (Gherasim et al., 2006).

We developed a measurement system for the acquisition, storage and processing of the voltage, current and wind speed time-series required by the standard. In order to provide more flexibility to the measurement system, instead of using a commercial equipment, we chose the implementation of our own system. The main rationale of our system is to divide the whole measurement into independent processes:

1. The recording and storage of the wind, voltage and current time-series.

2. The off-line measurement and assessment of the power quality characteristics by post-processing the stored time-series.

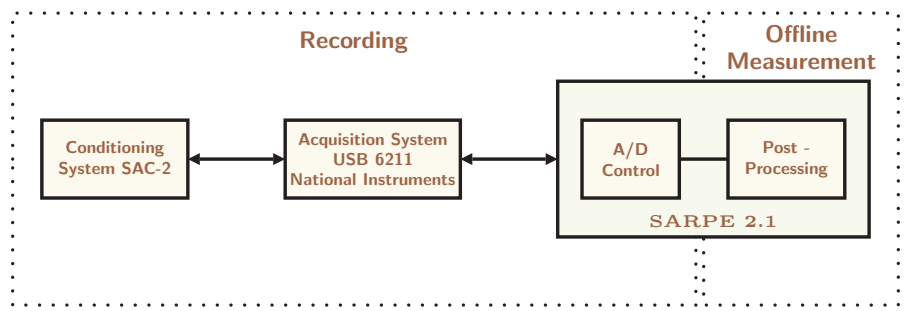

Fig. 9. Scheme of the measurement system. 
To perform those processes we developed two interconnected sub-systems: a signal conditioning system (SAC-2) and a control system (SARPE 2.1). The scheme of the overall measurement system is shown in Fig. 9. The conditioning system is a hardware module transforming the three-phase voltage and current, as well as the wind speed, to the appropriate levels for the post-processing. This operation is managed by the control system. This is a software tool that controls the acquisition and stores the voltage, current and wind speed time-series. The control system also includes a post-processing module that works off-line by reading the recorded time-series and calculates the parameters of the power quality characteristics of the wind turbine.

\subsection{Conditioning system SAC-2}

This system converts the voltage, current and wind speed input levels to the appropriate levels for the final measurement. Fig. 10 shows a photograph of the developed hardware platform, SAC-2.

For a precise conditioning of the input levels, this hardware platform provides four voltage channels and four different scales per channel (see Table 2 (a)).

There are also four current channels, and four different types of current sensors can be used (see Table 2 (b)). There are two additional analog channels to register wind characteristics.

The system provides several clocks to use as external sampling frequencies in the acquisition by the control module. The first set of sampling frequencies allows the use of a number of samples per cycle of $50 \mathrm{~Hz}$ always corresponding to a power of $2\left(f_{s}=1600,3200,6400,12800\right.$ and $25600 \frac{S}{S}$ ). A second set provides a number of samples per 10 cycles of $50 \mathrm{~Hz}$ or 12 cycles of $60 \mathrm{~Hz}$ corresponding to a power of $2\left(f_{s}=1280,2560,5120,10240\right.$ and $\left.20480 \frac{S}{S}\right)$. This second group of sampling frequencies makes possible the implementation of the harmonics and interharmonics measurement method specified by the standard. Each channel includes a fifth order Butterworth anti-aliasing filter with adjustable cutoff frequency. A phase-locked loop (PLL) synchronizes the sampling rate to the first channel grid frequency, either 50 or 60 $\mathrm{Hz}$.

The system also includes four digital inputs, activated by dry contacts, to trigger the start of the acquisition by the control system.

\subsection{Control system SARPE 2.1}

The control system is a MatLab tool running on a PC laptop and consists of two modules: the acquisition module and the post-processing module.
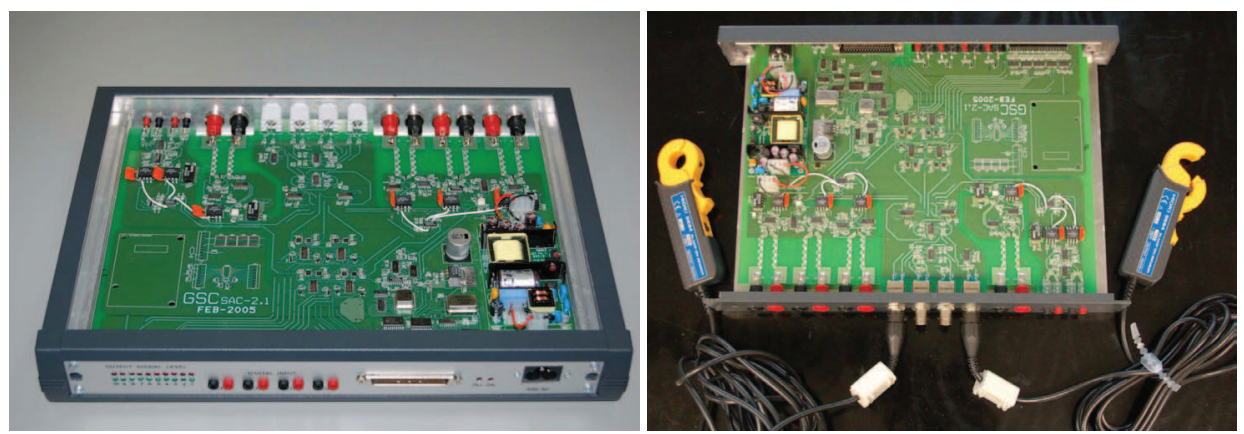

Fig. 10. Layout of the conditioning system, SAC-2. 
(b) Working ranges for the current sensors.

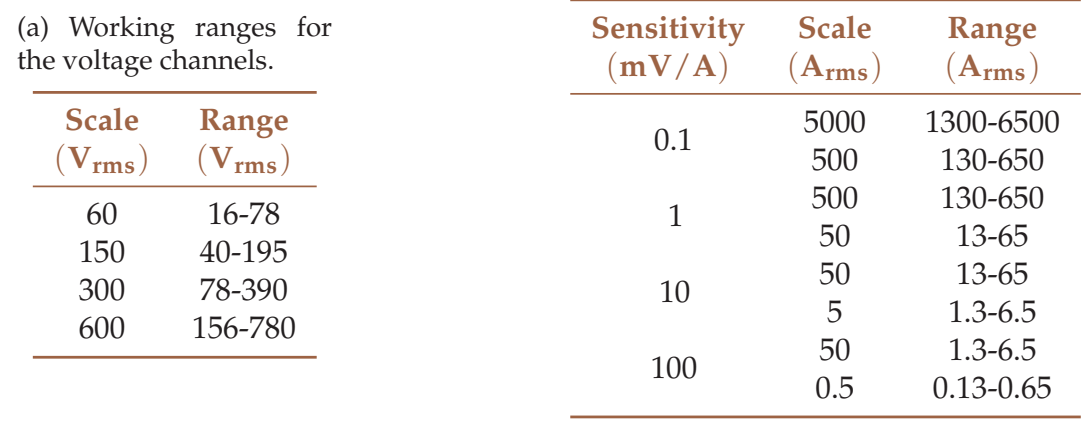

Table 2. Conditioning system working range.

The acquisition module manages both the acquisition and the recording operations. Its main functions are:

1. Acquisition of the conditioned signals using the DAQ 6062E card from National Instruments (12-bit resolution).

2. Selection of different parameters that configure the register:

a. Internal clock from the acquisition card or external clock from the conditioning system.

b. Sampling frequency.

c. Use of the anti-aliasing filters.

d. Activation of the PLL.

e. Channels to be recorded.

f. Scale of each selected voltage and current channels.

h. Duration of the register.

3. Checking the functional status of the wind turbine to validate the storage of the corresponding time-series.

4. Selection of the trigger type:
a. Delayed start.
b. Digitally controlled start.

5. Communication by GSM/GPRS system to remotely control the status of the registering process.

On the other hand, the post-processing module recovers the recorded sampled data and processes them according to the procedures specified by the IEC 61400-21 standard.

The off-line processing provides several advantages for the wind turbine certification process. Since the power quality standards may change, the off-line processing makes it easier to incorporate these changes by software modifications. In this sense, this method of post-processing allows the analysis of the waveforms that have produced a specific power quality characteristic. It is not necessary to retest a specific wind turbine to calculate the characteristics. Another advantage is that all parties involved in the certification process have access to the stored information. 


\section{Case study of power quality characteristic of grid-connected wind turbines}

There are not too many works assessing the power quality in wind farms according to the IEC 61400-21 standard (Foussekis et al., 2003; Srensen, 2001; Srensen et al., 2007). This section shows the results of measurements performed on two wind turbines with different constructive characteristics and located in an experimental wind farm in the northwest of Spain ${ }^{1}$. The first tested wind turbine (WT1) corresponds to a machine with a double speed asynchronous generation system ( 4 and 6 poles), fixed sail passage and fixed generator speed, with a nominal power of $660 \mathrm{Kw}$ and nominal voltage of $690 \mathrm{~V}$. In this wind turbine, a total of 135 records were registered under different wind speed and power conditions, each record containing a current and voltage $10 \mathrm{~min}$ time-series. The second wind turbine (WT2) has a 4-pole synchronous generating system and electronic power control, variable sail passage and variable generator speed, and it provides a nominal power of $800 \mathrm{KW}$ and a nominal voltage of $1000 \mathrm{~V}$. In this wind turbine, a total of 75 voltage and current $10 \mathrm{~min}$ time-series were recorded under different wind speed and power conditions.

Voltage fluctuations and harmonic and interharmonic content of the registered records are analyzed hereunder.

\subsection{Voltage fluctuations}

Each set of measured voltage-current time-series pair $u_{m}(t), i_{m}(t)$ is used as input to calculate the fictitious voltage $u_{f i c}(t)$ on the fictitious grid. This has been done for the four different network impedance phase angles $\left(\psi_{k}\right)$ specified in the IEC 61400-21 standard, using a short-circuit apparent power of $S_{k, f i c}=20 \cdot S_{n}$.

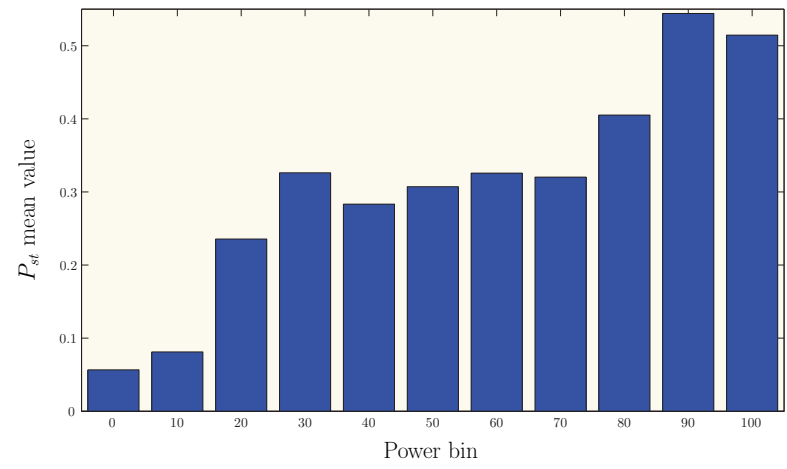

Fig. 11. Mean values of $P_{s t, \text { fic }}$ in terms of the active power bins for WT1.

In order to calculate the voltage $u_{0}(t)$ required to obtain $u_{f i c}(t), u_{m}(t)$ has been filtered with an IIR band-pass notch filter; the filter implementation is based on anticausal zero-phase technique. Each of the obtained $u_{f i c}(t)$ (one for each $\psi_{k}$ for each $u_{m}-i_{m}$ pair) has been input to an IEC 61000-4-15 compliant flickermeter to obtain the flicker severity value $P_{s t, f i c}$.

Fig. 11 shows the results obtained for the first wind turbine working with a network impedance phase angle $\psi_{k}=85^{\circ}$. The $135 P_{\text {st, fic }}$ values obtained for this wind turbine have been grouped according to the power of the machine, for the operation of the wind turbine within the active power bins $0,10,20, \ldots, 100 \%$ of $P_{n}$. The first bin corresponds to $P<5 \%$

\footnotetext{
${ }^{1}$ The authors would like to thank SOTAVENTO GALICIA S.A. (Spain) for making the signals available free of charge for the purpose of this work.
} 


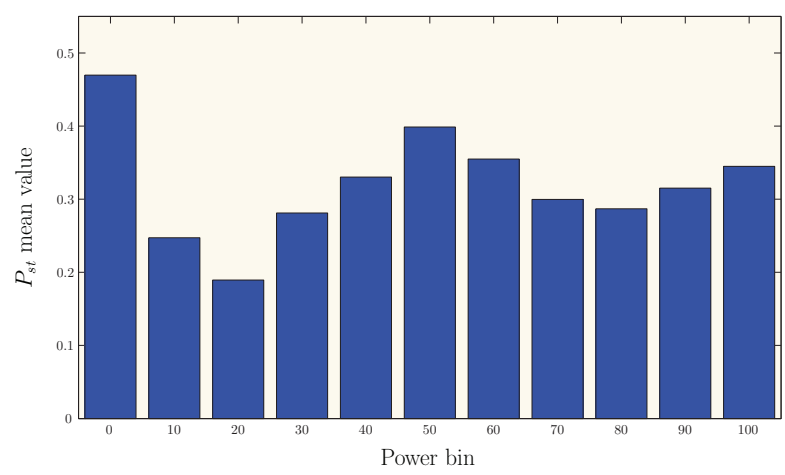

Fig. 12. Mean values of $P_{s t, f i c}$ in terms of the active power bins for WT2.

of $P_{n}$; the last one to $P>95 \%$ of $P_{n}$; the intermediate bins correspond to $10 \%$-wide ranges centered in the bin midpoints. It can be observed that $P_{s t, f i c}$ values increase as the working power increases.

In the same way, Fig. 12 shows the $P_{\text {st,fic }}$ values obtained for the $75 u_{\text {fic }}$ associated to the second wind turbine; the values are also given for $\psi_{k}=85^{\circ}$, as in the previous case. In this case the $P_{s t, f i c}$ values are high when the machine operates at low power.

\subsection{Current harmonics and interharmonics}

The harmonic and interharmonic content of each current signal has been obtained according to the IEC 61000-4-7 standard. A 10-cycle (in a $50 \mathrm{~Hz}$ system, approximately $200 \mathrm{~ms}$ ) rectangular window has been used. For each window within a 10 min period, the Discrete Fourier Transform (DFT) has been calculated and the resulting spectral lines have been grouped to obtain the harmonic subgroups (HS) and the interharmonic centered subgroups (ICS).

The resulting HS and ICS time-series have been smoothed using a first order low-pass filter with a time constant of $1.5 \mathrm{~s}$. The smoothing filter introduces a transient; in order to eliminate this transient the first 10 seconds of each HS and ICS have been suppressed. Afterwards the HS and ICS RMS value has been calculated. Therefore given a $10 \mathrm{~min}$ current time-series, a single value is obtained for each HS and ICS. In order to illustrate the effect of the smoothing process, Fig. 13 shows the time evolution of the $7^{\text {th }}$ harmonic subgroup $I_{s g, 7}$ (a) and the $7^{\text {th }}$ interharmonic centered subgroup $I_{i s g, 7}($ b) of phase1-current in a 10 min register recorded in the first wind turbine while working at $53 \%$ of nominal power. The evolution of the RMS value of $I_{s g, 7}$ and $I_{i s g, 7}$ along the 10-cycle intervals, i.e. the input to the smoothing low-pass filter, is represented in blue; the output from the smoothing low-pass filter is shown in red. It can be observed that smoothing reduces the abrupt changes produced between two adjacent windows.

Fig. 14 shows in more detail the initial $20 \mathrm{~s}$ of Fig. 13. The transient produced by the smoothing process is clearly observed. This transient has to be suppressed so that it is not taken into consideration in the calculation of the HS and ICS of the analyzed record.

Fig. 15 shows the HS and ICS content (up to $12^{\text {th }}$ order harmonic) of phase1-current in the same $10 \mathrm{~min}$ record of the first wind turbine in which Fig. 13 and 14 are based. A high contribution of $5^{\text {th }}, 7^{\text {th }}$ and $11^{\text {th }}$ harmonics can be observed, whereas the rest of harmonics and all the interharmonics take very low values. 


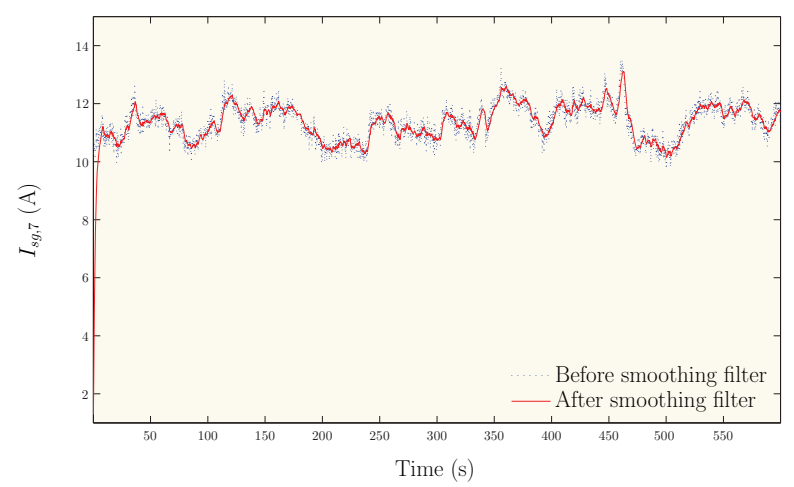

(a) RMS value of $7^{\text {th }}$ harmonic subgroup.

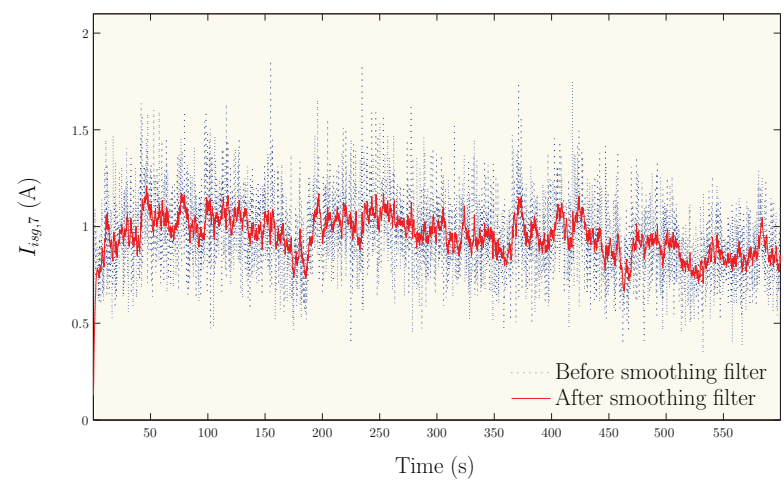

(b) RMS value of $7^{\text {th }}$ interharmonic centered subgroup.

Fig. 13. Effect of smoothing.

Fig. 16 shows the same information as Figure 15, but for a 10 min record of the second wind turbine. The mean power of the selected record is also $53 \%$ of $S_{n}$, as in the first turbine. The comparison between Fig. 15 and 16 shows that harmonic and interharmonic content distribution is completely different in both turbines. In the second one, harmonic content is more uniformly distributed among all the HS and ICS.

The 10 min averages of each subgrouped harmonic and interharmonic have been calculated for each of the 13510 -min time-series recorded in the first wind turbine. Fig. 17 represents the maximum 10-min averages of $7^{\text {th }}$ harmonic (a) and $7^{\text {th }}$ interharmonic (b) in each $10 \%$ power bin. The first bin corresponds to $P<5 \%$ of $P_{n}$; the last one to $P>95 \%$ of $P_{n}$; the intermediate bins correspond to $10 \%$-wide ranges centered in the bin midpoints $(10,20, \ldots, 90)$. The results are shown in percentage of $I_{n}$.

The same process is performed with the phase1-current of the 75 records of the second turbine. Fig. 18 shows the maximum 10-min averages of $7^{\text {th }}$ harmonic (a) and $7^{\text {th }}$ interharmonic (b) in percentage of $I_{n}$ in each $10 \%$ power bin.

The comparison between Fig. 17 and 18 shows that the maximum value of $7^{\text {th }}$ harmonic content is higher in the first wind turbine than in the second one for nearly all the power 


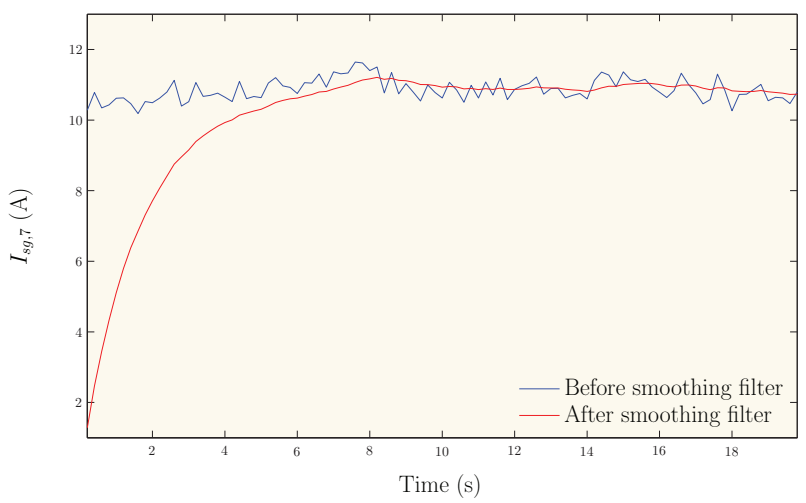

(a) RMS value of $7^{\text {th }}$ harmonic subgroup.

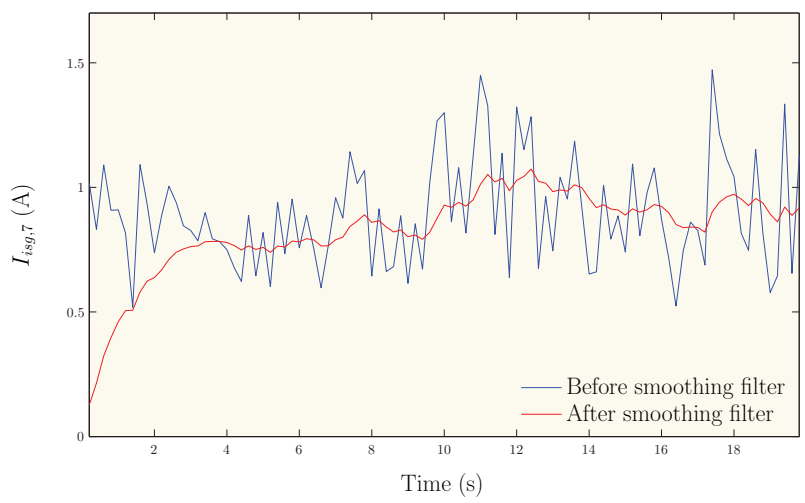

(b) RMS value of $7^{\text {th }}$ interharmonic centered subgroup.

Fig. 14. Transient time due to smoothing.

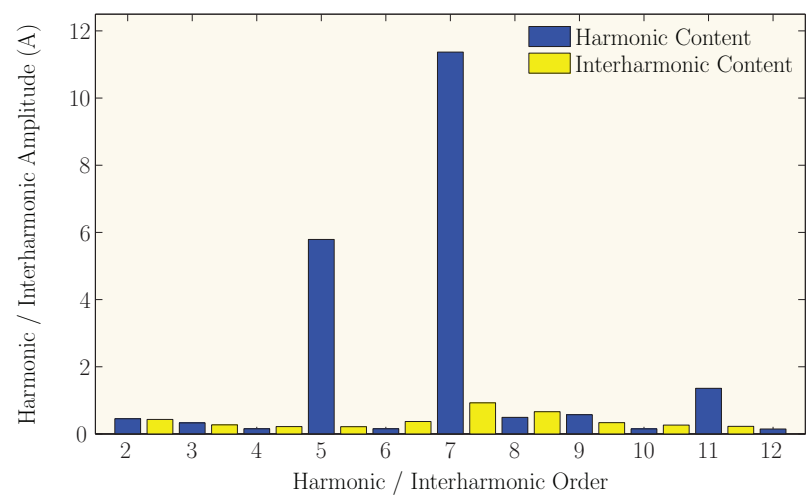

Fig. 15. Harmonic and Interharmonic content: WT1, $\frac{P}{S_{n}}=53 \%$. 


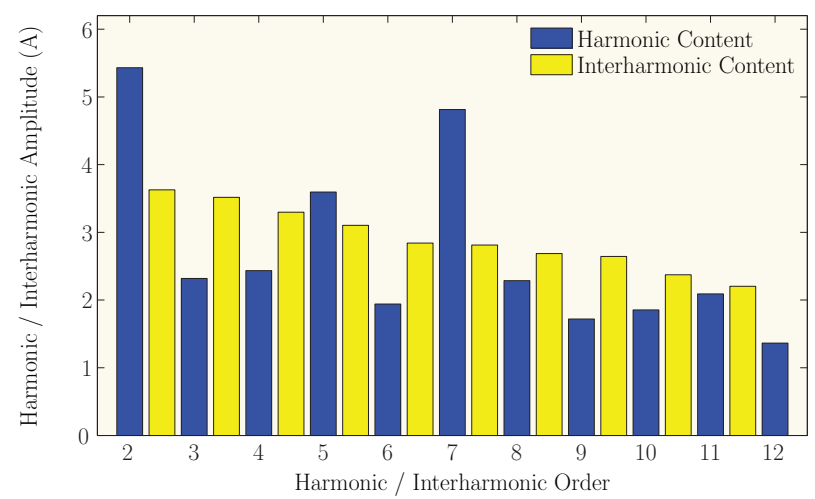

Fig. 16. Harmonic and Interharmonic content: WT2, $\frac{P}{S_{n}}=53 \%$.

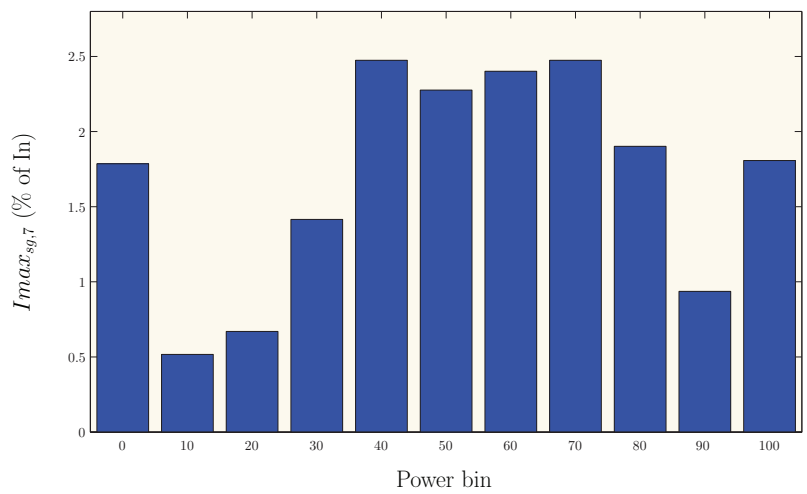

(a) $7^{\text {th }}$ harmonic subgroup.

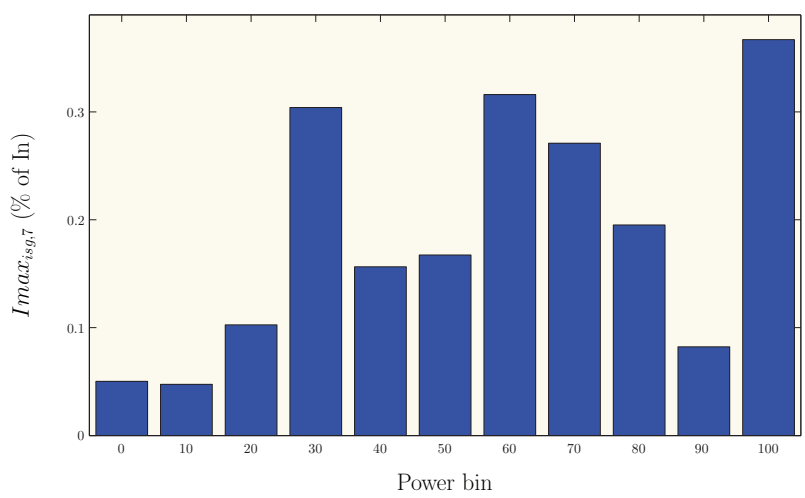

(b) $7^{\text {th }}$ interharmonic centered subgroup.

Fig. 17. WT1: Maximum 10-min average of a given harmonic/interharmonic (in $\%$ of $I_{n}$ ) in each power bin. 


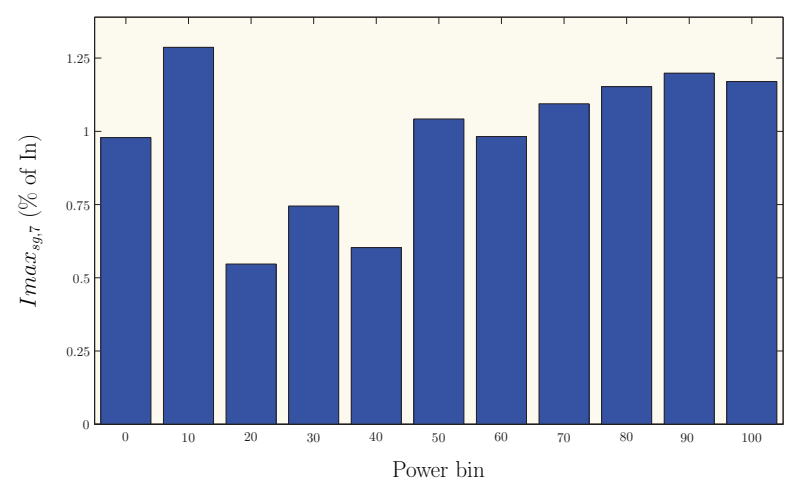

(a) $7^{\text {th }}$ harmonic subgroup.

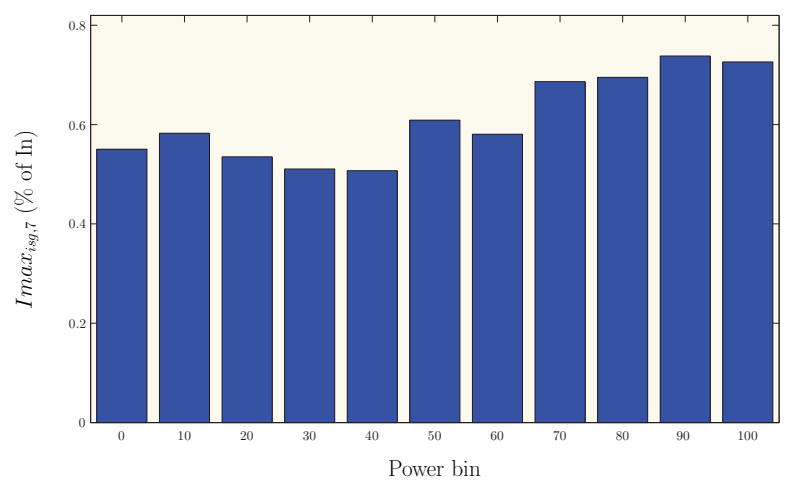

(b) $7^{\text {th }}$ interharmonic centered subgroup.

Fig. 18. WT2: Maximum 10-min average of a given harmonic/interharmonic (in \% of $I_{n}$ ) in each power bin.

bins. The reverse consideration is true for $7^{\text {th }}$ interharmonic: its content is lower in the first wind turbine than in the second one for all the power bins.

\section{Conclusions}

Power injection from wind turbines affects substantially the power quality. This chapter described the main parameters involved in the assessment of the power quality of grid-connected wind turbines. The definition of those parameters and the procedures and methods for their assessment are compiled in the IEC 61400-21 standard. This text has become the reference normative for the certification of the grid-connected wind turbines in terms of power quality. According to it there are seven parameters compromising the required power quality characteristic of a wind turbine: voltage fluctuations or flicker; harmonics and interharmonics; voltage drops; active power; reactive power; grid protection and reconnection time.

The implementation of the measurement and assessment procedures specified by the standard requires a deep knowledge and experience on power quality issues. Moreover, all the 
procedures require the storage and processing of a great amount of data from voltage, current and wind time-series. For that purpose we developed our own measurement system, a useful tool specifically designed for the assessment of the power quality of a grid-connected wind turbine. This system acquires, stores and processes the voltage, current and wind speed time-series required by the standard, providing the output parameters specified by the standard for the assessment of the power quality characteristics.

The methods to assess the voltage fluctuations and harmonic content are particularly demanding. Their measurements are based on complex functional systems and advanced signal processing techniques. We have extensively detailed some of these techniques and we have applied them to a case study based on the analysis of both parameters on two wind turbines with different constructive characteristics and located in an experimental wind farm in the northwest of Spain. Since there are not too many experimental works assessing the power quality in wind farms according to the IEC 61400-21 standard, this work can be useful to enlarge the knowledge about the influence of the wind turbines on the power quality.

\section{References}

Ackerman, T. (2005). Wind Power in Power Systems., John Wiley \& Sons, Ltd.

Foussekis, D., Kokkalidis, F., Tentzerakis, S. \& Agoris, D. (2003). Power quality measurements on different types of wind turbines operating in the same wind farm, Proceedings on European Wind Energy Conference and Exhibition .

Gallo, D., Landi, C. \& Pasquino, N. (2006). Design and Calibration of an Objective Flickermeter, IEEE Transactions on Instrumentation and Measurement 55(6): 2118-2125.

Gherasim, C., Croes, T., den Keybus, J. V., Driesen, J. \& Belmans, R. (2006). Development of a flickermeter for grid-connected wind turbines using a DSP-based prototyping system, Instrumentation and Measurement, IEEE Transactions on 55(2): 550-556.

Gutierrez, J., Ruiz, J., Leturiondo, L. \& Lazkano, A. (2008). Filcker Measurement System for Wind Turbine Certification, IEEE Transactions on Instrumentation and Measurement 57(12): 375-382.

IEC-61000-4-15 Ed. 2.0 (2010). Electromagnetic compatibility (emc) Ü part 4: Testing and measurement techniques - section 15: Flickermeter functional and design specifications.

IEC-61000-4-7 (2002). Electromagnetic compatibility (emc) Ü part 4: Testing and measurement techniques - section 7: General guide on harmonics and interharmonics measurements and instrumentation, for power supply systems and equipment connected thereto.

IEC-61400-21 Ed. 2.0 (2008). Wind turbine generator systems. Part 21: Power quality requirements for grid connected wind turbines.

Key, T., Nastasi, D., Sakulin, H., Harding, J. \& Cooke, T. (1999). System Compatibility Research Project Final Report, Task 21: Power Line Monitors, Part II: Flickermeters, EPRI PEAC Corporation .

Lee, J. \& Devaney, M. (1994). Accurate measurement of line frequency in the presence of noiseusing time domain data, Proceedings of the $10^{\text {th }}$ IEEE Instrumentation and Measurement Technology Conference., pp. 1016-1019.

Mombauer, W. (1998). Calculating a new reference point for the IEC-flickermeter, European Transactions on Electrical Power 8(6): 429-436.

Ruiz, J., Gutierrez, J. \& Irusta, U. (2007). Singular Frequencies in Rectangular Fluctuations in the IEC Flickermeter, IEEE Transactions on Power Delivery 22(2): 1255-1256. 
Ruiz, J., Gutierrez, J., Lazkano, A. \& Ruiz de Gauna, S. (2010). A Review of Flicker Severity Assessment by the IEC Flickermeter, IEEE Transactions on Instrumentation and Measurement 59(8): 2037-2047.

Srensen, P. (2001). European Wind Turbine Testing Procedure Developments. Task 2: Power Quality, Ris National Laboratory .

Srensen, P., Cutululis, N., Lund, T., Hansen, A., Srensen, T., Hjerrild, J., Donovan, M., Christensen, L. \& Nielsen, H. (2007). Power quality issues on wind power installations in denmark, Power Engineering Society General Meeting, 2007. IEEE, pp. 1-6.

WG2CIGRÉ (2004). Test Protocol for IEC Flickermeter used in Power System Voltage Monitoring.

Widrow, B. \& Stearns, S. (1985). Adaptive Signal Processing, Prentice Hall. 


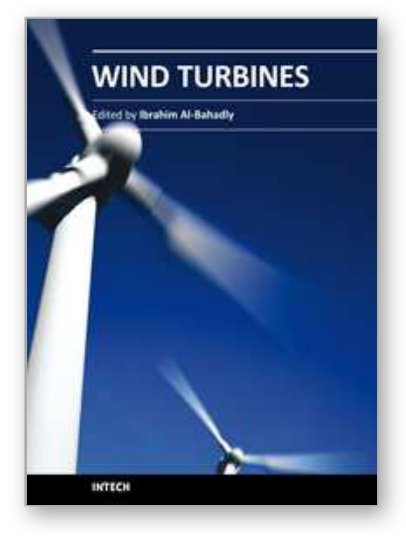

\author{
Wind Turbines \\ Edited by Dr. Ibrahim Al-Bahadly
}

ISBN 978-953-307-221-0

Hard cover, 652 pages

Publisher InTech

Published online 04, April, 2011

Published in print edition April, 2011

The area of wind energy is a rapidly evolving field and an intensive research and development has taken place in the last few years. Therefore, this book aims to provide an up-to-date comprehensive overview of the current status in the field to the research community. The research works presented in this book are divided into three main groups. The first group deals with the different types and design of the wind mills aiming for efficient, reliable and cost effective solutions. The second group deals with works tackling the use of different types of generators for wind energy. The third group is focusing on improvement in the area of control. Each chapter of the book offers detailed information on the related area of its research with the main objectives of the works carried out as well as providing a comprehensive list of references which should provide a rich platform of research to the field.

\title{
How to reference
}

In order to correctly reference this scholarly work, feel free to copy and paste the following:

J.J. Gutierrez, J. Ruiz, P. Saiz, I. Azcarate, L.A. Leturiondo and A. Lazkano (2011). Power Quality in GridConnected Wind Turbines, Wind Turbines, Dr. Ibrahim Al-Bahadly (Ed.), ISBN: 978-953-307-221-0, InTech, Available from: http:/www.intechopen.com/books/wind-turbines/power-quality-in-grid-connected-wind-turbines

\section{INTECH}

open science | open minds

\section{InTech Europe}

University Campus STeP Ri

Slavka Krautzeka 83/A

51000 Rijeka, Croatia

Phone: +385 (51) 770447

Fax: +385 (51) 686166

www.intechopen.com

\section{InTech China}

Unit 405, Office Block, Hotel Equatorial Shanghai

No.65, Yan An Road (West), Shanghai, 200040, China

中国上海市延安西路65号上海国际贵都大饭店办公楼405单元

Phone: +86-21-62489820

Fax: +86-21-62489821 
(C) 2011 The Author(s). Licensee IntechOpen. This chapter is distributed under the terms of the Creative Commons Attribution-NonCommercialShareAlike-3.0 License, which permits use, distribution and reproduction for non-commercial purposes, provided the original is properly cited and derivative works building on this content are distributed under the same license. 